Part of Journal of Research of the National Bureau of Standards, Volume 19, July 1937

\title{
NATURE OF THE ACID-DYEING PROCESS
}

\author{
By Arthur L. Smith and Milton Harris ${ }^{1}$
}

\section{ABSTRACT}

The dye-combining capacity of untreated wool has been determined for the typical acid dye, orange II, and shown to be equal to the acid-combining capacity. Treatments with nitrous acid, hydrogen peroxide, sodium hypochlorite, and strong solutions of sulfuric acid decrease the basicity of the wool and correspondingly decrease the affinity for acid dyes. Chlorinated wool absorbs acid dyes at a greater initial rate than untreated wool, but at equilibrium the latter absorbs more dye. The resist to acid dyes produced in the sulfuric-acid-carbonizing process is caused by the conversion of basic amino groups to sulfamic-acid derivatives. The results of the investigation constitute further evidence in favor of the chemical theory of acid dyeing.

\section{CONTENTS}

Page

I. Introduction

II. Acid-dye-combining capacity of untreated wool

III. Effect of various treatments on the acid-dye-combining capacity of wool_ 83

1. Effect of nitrous acid. 83

2. Effect of hydrogen peroxide 84

3. Affinity of chlorinated wool for acid dyes

4. Nature of the resist produced in wool by the carbonizing process -84

IV. References

\section{INTRODUCTION}

The complexity of dyeing processes has given rise to many theories, all of which may be classified under the general headings of chemical or physical. However, the more recent work of Elöd [1] ,2 PoraiKoschitz [2], Speakman [3], and their collaborators leaves little doubt that the reaction of wool with acid dyes is governed by chemical laws and consists in the neutralization of the basic groups in the fiber by the acidic groups of the dye molecules. The data in the present report, obtained by a somewhat different approach to the problem, constitute further evidence in favor of the chemical theory for this type of dyeing.

\section{ACID-DYE-COMBINING CAPACITY OF UNTREATED WOOL}

The majority of the investigations relating to the mechanism of the acid-dyeing process have been made under conditions which closely approximate those used in the commercial dyeing of wool. Unfortunately, the amount of dye required for such a dyeing constitutes only a small fraction of the total dye which the wool is capable of absorbing and, as a result, data from such investigations have little quantitative significance.

\footnotetext{
${ }^{1}$ Research Associates at the National Bureau of Standards, representing the American Association of Textile Chemists and Colorists. The work reported here was aided by grants from the Textile Foundation, Inc., and the Eavenson \& Levering Co.

${ }_{2}^{2}$ Figures in brackets throughout the text correspond to the numbered references at the end of this paper.
} 
Assuming that the acid-dyeing process consists in a reaction between the dye and the basic groups of the wool, then a given amount of wool should combine with equal molecular proportions of acid or acid dye. The acid-combining capacity of wool has been shown by several investigators $[4,5,6,7]$ to be about 0.80 millimole of acid per gram of wool, and it has also been shown [8] that the combined acid may be accounted for by the free amino groups and by the guanidine nucleus of the arginine in wool. The acid-dye-combining capacity of the wool was determined in the present investigation by the following procedure. Yarn, prepared from wool which had been solvent-scoured, was further purified by extraction in a Soxhlet apparatus with alcohol and with ether, and finally was washed in water at $140^{\circ} \mathrm{F}$. The dye was a purified sample of orange II, analysis of which showed 90.6 percent of dye, 1.26 percent of sodium chloride, and 8.15 percent of moisture. The dyeings were boiled under a reflux condenser in a solution containing 1 millimole of dye per gram of wool, the ratio of wool to solution being $1: 200$. Sufficient sulfuric acid was added to obtain a $\mathrm{pH}$ of about 1.3 , which is the $\mathrm{pH}$ shown by Elöd [1] to be necessary for the maximum absorption of acid dyes. The amount of dye absorbed from the solution was measured with a colorimeter by comparing the color of aliquots from the dye bath with that of solutions containing known amounts of the dye. The limiting absorption of dye appeared to be reached in 1.5 hours, when 0.85 millimole of dye per gram of wool had been absorbed. This value became slightly larger with increased time of dyeing, but on examination of the dye liquors, it was found that small particles of wool fibers were being split off.

This diffculty was readily overcome by lowering the temperature of the dye bath to $120^{\circ} \mathrm{F}$, the only other effect being a considerable increase in the time necessary to reach equilibrium. The results of dyeing experiments at this temperature in a solution $0.1 \mathrm{~N}$ with respect to hydrochloric acid ${ }^{3}$ are shown in table 1. Equilibrium appears to be reached after about 12 hours. All subsequent dyeings were done under these conditions for 18 hours in order to be well within the equilibrium region.

TABLE 1.-Rate of absorption of orange II from a solution at $120^{\circ} \mathrm{F}$ containing 1 millimole of dye per gram of wool, the ratio of wool to solution being 1:200

\begin{tabular}{|c|c|}
\hline Time & $\begin{array}{c}\text { Amount of } \\
\text { orange II } \\
\text { absorbed }\end{array}$ \\
\hline Hours & $\begin{array}{c}\text { Millimole per } \\
\text { gram of wool } \\
2\end{array}$ \\
3.3 & 0.28 \\
5 & .38 \\
8 & .63 \\
9 & .71 \\
12 & .73 \\
21.3 & .81 \\
22 & .85 \\
\hline
\end{tabular}

\footnotetext{
3 The $\mathrm{pH}$ of the dye bath was maintained with $0.1 \mathrm{NHCl}$, because in subsequent experiments, it was necessary to find out whether sulfuric acid was split off from wool which had previously been treated with concentrated solutions of sulfuric acid.
} 
The results of a similar set of equilibrium dyeings, using $0.5,1.0$, and 1.5 millimoles of dye per gram of wool, are recorded in table 2 and show that the amount of dye absorbed is independent of the concentration, providing sufficient dye is present to react with all of the basic groups in the fiber.

The solution was $0.1 \mathrm{~N}$ with respect to hydrochloric acid.

TABLE 2.-Effect of varying the concentration of the dye bath on the amount of dye absorbed by wool at equilibrium

\begin{tabular}{|c|c|}
\hline $\begin{array}{c}\text { Concentration } \\
\text { of orange II } \\
\text { in dye bath }\end{array}$ & $\begin{array}{c}\text { Amount of } \\
\text { orange II } \\
\text { absorbed }\end{array}$ \\
\hline $\begin{array}{c}\text { Millimoles per } \\
\text { gram of wool } \\
0.50\end{array}$ & $\begin{array}{c}\text { Millimoles per } \\
\text { gram of wool } \\
0.49 \\
1.00\end{array}$ \\
1.50 & .83 \\
\hline
\end{tabular}

The values of 0.82 and 0.83 millimole of orange II absorbed per gram of wool are in good agreement with the acid-combining capacity and with the value 0.8 obtained by Porai-Koshitz [2] who used the dye eosine. He worked with the ammonium salts and showed that the amount of ammonia liberated corresponded to the amount of dye absorbed.

\section{EFFECT OF VARIOUS TREATMENTS ON THE ACID- DYE-COMBINING CAPACITY OF WOOL}

\section{EFFECT OF NITROUS ACID}

One of the arguments that has been repeatedly used against the chemical theory of acid dyeing is based on what appears to be the unchanged affinity for acid dyes of wool treated with nitrous acid. Trotman [9], Paddon [10], and Benz and Farrell [11] attempted to destroy this affinity by deamination of the wool, and all concluded that treatment of wool with nitrous acid had little if any effect on the absorption of acid dyes by the fiber. All of these workers failed to realize that deamination, even when produced by prolonged treatment with nitrous acid, only partially destroys the basic properties of wool $[3,8]$. In addition, they used amounts of dyes which would be readily taken up by the remaining basic groups in the wool.

More recently, however, Speakman and Stott (3) working with high concentrations of dyes and samples of wool which had been treated with nitrous acid for nearly 100 hours, demonstrated that the affinity of deaminated wool for acid dyes is far less than that of untreated wool. The results they obtained were confirmed by similar experiments in the present investigation, under far less drastic conditions of deamination. A sample of wool yarn was treated with a 10-percent solution of nitrous acid at room temperature for 3 hours, after which it was washed for 48 hours in distilled water. The treated sample had acid- and acid-dye-combining capacities of 0.5 and 0.4 millimole per gram, respectively. 


\section{EFFECT OF HYDROGEN PEROXIDE}

In an investigation of the effect of hydrogen peroxide on the basic groups in wool [12], it was found that the acid-combining capacity decreased with increased oxidation. The magnitude of these changes was so great as to suggest a similar determination of the acid-dyecombining capacity. Samples of wool were oxidized for different lengths of time with a 3-percent neutral solution of hydrogen peroxide at $120^{\circ} \mathrm{F}$. The effect of the treatment on the basic properties of the wool is shown in table 3 . Both the acid-and the acid-dye-combining capacities decrease at about the same rate with increase in time of oxidation.

TABLE 3.-Effect of oxidizing wool with 3 percent of hydrogen peroxide at $120^{\circ} \mathrm{F}$ for different lengths of time on the acid-and the acid-dye-combining capacities

\begin{tabular}{|c|c|c|}
\hline $\begin{array}{c}\text { Duration of } \\
\text { oxidation }\end{array}$ & $\begin{array}{c}\text { Acid-dye- } \\
\text { combining } \\
\text { capacity }\end{array}$ & $\begin{array}{c}\text { Acid-combin- } \\
\text { ing capacity }\end{array}$ \\
\cline { 2 - 3 } Hours & $\begin{array}{c}\text { Millimole per } \\
\text { gram }\end{array}$ & $\begin{array}{c}\text { Millimole per } \\
\text { gram }\end{array}$ \\
0 & 0.78 & 0.77 \\
3 & .77 & .73 \\
7 & .68 & .60 \\
16 & .52 & .43 \\
24 & .54 & .44 \\
43 & .34 & .33 \\
\hline
\end{tabular}

\section{AFFINITY OF CHLORINATED WOOL FOR ACID DYES}

Treatment of wool with chlorine or bromine has been claimed by various workers [13] to increase the dye-absorbing capacity of wool. Such claims appear to contradict the well-known ease of oxidation of amino groups by halogens [14] as well as the findings of the present investigation, which show that the acid-combining capacity of wool treated with a sodium hypochlorite solution (containing at $\mathrm{pH} 8$, 8 percent of active chlorine, based on the weight of the wool) decreases from 0.79 to 0.71 millimole. This apparently anomalous behavior of halogenated wool is readily explained by the determination of the rate of absorption of acid dye by untreated wool and by wool treated with the sodium hypochlorite solution containing 8 percent of active chlorine. The curves in figure 1 show that the initial rate of absorption of dye is much higher for the chlorinated sample, but that at equilibrium slightly more dye is taken up by the untreated sample. The increased rate of absorption of the dye appears to be caused in part by changes in the physical structure of the fiber during chlorination, a factor previously noted by Trotman [16].

\section{NATURE OF THE RESIST PRODUCED IN WOOL BY THE CARBONIZING PROCESS}

After treatment by the carbonizing process, wool exhibits a decreased affinity for acid dyes and a correspondingly increased affinity for basic dyes. Since a large portion of commercial wool is dyed with acid dyes, this alteration of the affinity of the fiber for dyes is commonly referred to as a resist, although strictly speaking, it is only a resist to acid dyes. The factors which influence the formation of the resist on wool have been pointed out by Ryberg [16]. 
The present studies on the nature of the acid-dyeing process indicated that the resist was probably formed by decreasing the basic properties of the fiber. However, a mechanism which would account for the decrease in the basicity during carbonizing was not suggested until recently when Harris, Mease, and Rutherford [17] showed that, in addition to a reversible reaction of wool with sulfuric acid, there was a possible irreversible reaction. These are shown in the following equations:

$$
\begin{gathered}
\mathrm{RNH}_{2}+\mathrm{H}_{2} \mathrm{SO}_{4} \rightleftharpoons \mathrm{RNH}_{3} \cdot \mathrm{HSO}_{4} \\
\mathrm{RNH}_{2}+\mathrm{H}_{2} \mathrm{SO}_{4} \rightarrow \mathrm{RNHSO}_{3} \mathrm{H}+\mathrm{H}_{2} \mathrm{O},
\end{gathered}
$$

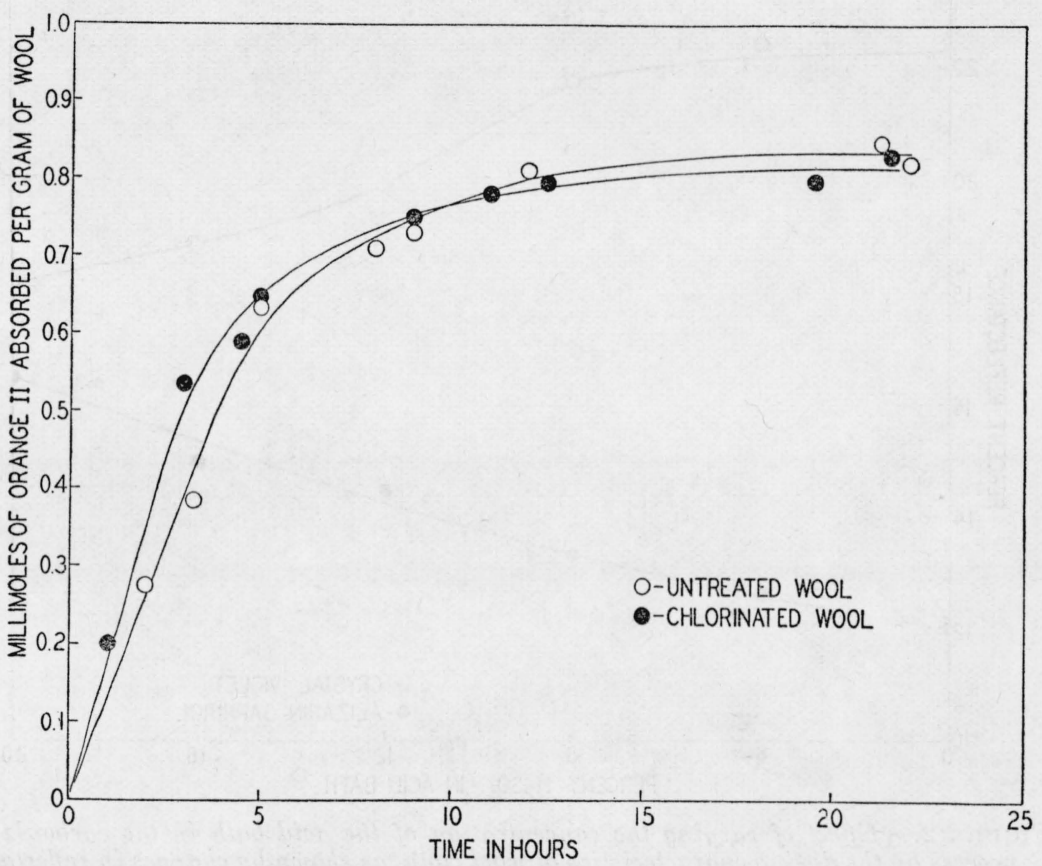

FIGURE 1.-Comparison of the rate of absorption of orange II by untreated wool wath that by wool which had been treated with a sodium hypochlorite solution containing 8 percent of active chlorine based on the weight of the wool.

where $\mathrm{R}$ represents the portion of the wool to which the basic group is attached.

Equation 1 indicates the reaction which is assumed to take place in dilute solutions of sulfuric acid. The acid in the compound formed in this reaction is reversibly held and is readily replaceable by acid dyes. On the other hand, the reaction represented in equation 2 appears to take place only under dehydrating conditions, for example, in the presence of strong solutions of sulfuric acid. The reaction of basic groups in wool with sulfuric acid, to form sulfamic acid derivatives according to equation 2, not only decreases the basic properties but also increases the acidic properties.

The results of that work immediately suggested that a similar reaction might occur in the carbonizing process, and would not only account for the decreased affinity for acid dyes but also for the increased 
affinity for basic dyes. Although the concentration of sulfuric acid in the acid-soaking bath seldom exceeds 5 percent by weight, the acid becomes concentrated on the fiber during the subsequent drying and baking processes and the reaction in equation 2 could occur.

That the formation of the resist is the result of producing a new compound of the sulfamic acid type is demonstrated by the following experiment. Samples of wool cloth were soaked for $15 \mathrm{~min}$ at $70^{\circ} \mathrm{F}$ in solutions of sulfuric acid, varying in concentration up to 20 percent by weight. The samples were immediately centrifuged to about 40 percent of condition, baked 15 minutes at $250^{\circ} \mathrm{F}$, and washed in running distilled water for about a week. The decrease in the acid-

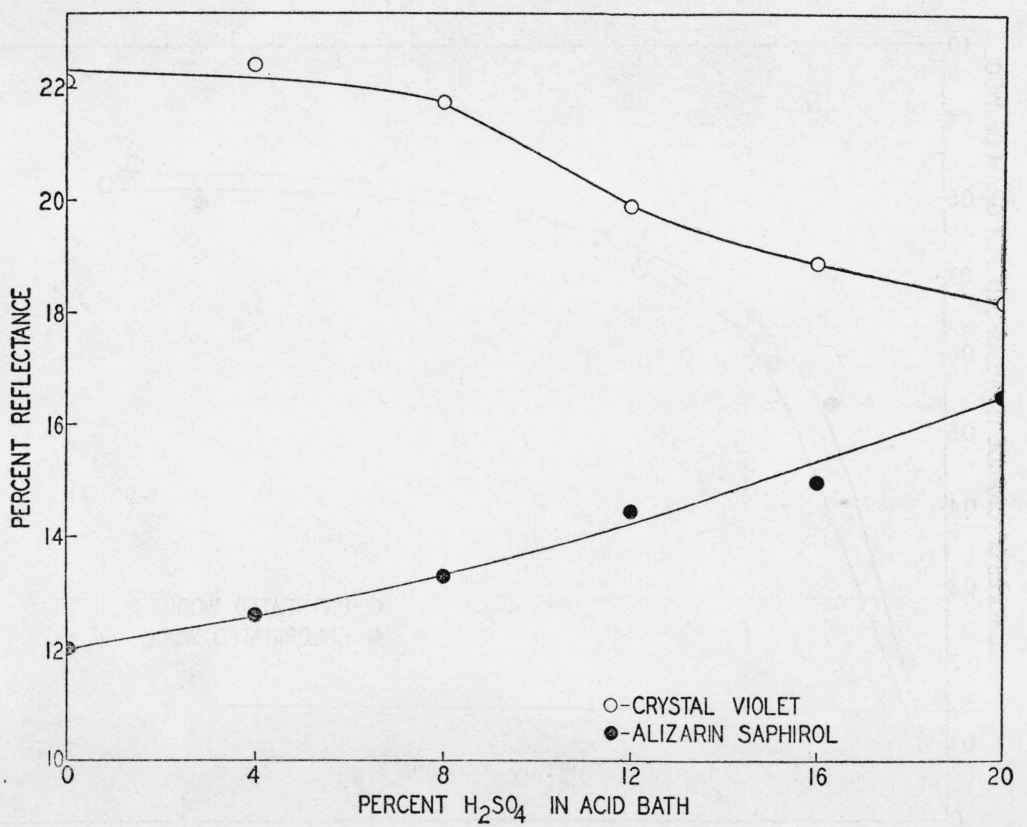

FIGURE 2.-Effect of varying the concentration of the acid bath in the carbonizing process on the dyeing characteristics of wool cloth, as shown by changes in reflectance of light at wave length 436 millimicrons for the samples dyed with crystal violet, and wave length 501 millimicrons for those dyed with alizarin saphirol.

and acid-dye-combining capacities and the increase in the alkalicombining capacity [17] and the sulfate content [18] with increasing concentration of acid in the soaking bath are shown in table 4 . Although good agreement between the decrease in acid-combining capacities and the increase in alkali-combining capacities and sulfate content was obtained, the decrease in the acid-dye-combining capacity is low. This discrepancy was accounted for when an examination of the dye baths showed the presence of sulfate. This indicated that hydrolysis of the sulfamic acid groups had occurred during the prolonged dyeing, thus regenerating some basic amino groups.

The data in table 4 also show that a large proportion of the basic groups in wool are still available for dyeing. Since the number of moles of dye per gram of wool used in commercial dyeings is very much smaller than the residual acid-dye-combining capacities, the 
visual differences in the color of commercially dyed, carbonized samples indicates that the bulk of the resist is formed on the surface of the fiber. The effect of varying the acid concentration of the soaking bath, as previously described, on dyeings which approximate those obtained commercially is shown in figure 2. Here the formation of the resist, as evidenced by the increase in reflectance of the samples dyed with alizarin saphirol, is accompanied by a corresponding increased affinity for basic dyes, as shown by the decrease in reflectance of the samples dyed with crystal violet.

TABLE 4.-Effect of varying the concentration of acid in the soaking bath used in the carbonizing process on the acidic and basic properties of wool

\begin{tabular}{|c|c|c|c|c|}
\hline $\begin{array}{c}\text { Concentration } \\
\text { of } \mathrm{H}_{2} \mathrm{SO}_{4} \text { in the } \\
\text { acid soaking } \\
\text { bath }\end{array}$ & $\begin{array}{c}\text { Decrease in } \\
\text { acid-dye-com- } \\
\text { bining capac- } \\
\text { ity }\end{array}$ & $\begin{array}{c}\text { Decrease in } \\
\text { acid-combin- } \\
\text { ing capacity }\end{array}$ & $\begin{array}{c}\text { Increase in } \\
\text { alkali-combin- } \\
\text { ing capacity }\end{array}$ & $\begin{array}{c}\text { Increase in } \\
\text { sulfate content }\end{array}$ \\
\cline { 2 - 4 } Percent & $\begin{array}{c}\text { Millimole per } \\
\text { gram }\end{array}$ & $\begin{array}{c}\text { Millimole per } \\
\text { gram }\end{array}$ & $\begin{array}{c}\text { Millimole per } \\
\text { gram }\end{array}$ & $\begin{array}{c}\text { Millimole per } \\
\text { gram }\end{array}$ \\
4 & 0.00 & 0.01 & 0.04 & 0.02 \\
8 & .01 & .13 & .11 & .09 \\
12 & .08 & .21 & .23 & .16 \\
20 & .08 & .24 & .30 & .18 \\
\hline .11 & .26 & .34 & .28 \\
\hline
\end{tabular}

\section{REFERENCES}

[1] Trans. Faraday Soc. 29, 327 (1932).

[2] Trans. Leningrad Chem. Tech. Inst. (USSR) 1, 157 (1934).

[3] J. Soc. Dyers Colourists 341 (1934).

[4] Ber. deut. chem. Ges. 53, 2164 (1920).

[5] Melliand Textilber. $\boldsymbol{\gamma}, 605$ (1926).

[6] J. prakt. Chem. 13\%, 179 (1933).

[7] J. Soc. Dyers Colourists 40, 408 (1924).

[8] J. Research NBS 14, 563 (1935) RP787.

[9] J. Soc. Dyers Colourists 40, 77 (1924).

[10] J. Phys. Chem. 26, 384 (1922).

[11] J. Soc. Chem. Ind. 16, 406 (1897).

[12] Unpublished results of investigation now in progress.

[13] Text. Colorist 52, 89 (1930).

[14] Ber. deut. chem. Ges. 42, 392, 2360 (1909).

[15] J. Soc. Chem. Ind. 41, 219T (1922).

[16] Am. Dyestuff Reptr. 23, 112 (1934).

[17] J. Research NBS 18, 343 (1937) RP980.

[18] J. Research NBS 13, 617 (1934) RP731.

Washington, May 18, 1937. 